\title{
A Career in Surgical Oncology: Finding Meaning, Balance, and Personal Satisfaction
}

\author{
Tait Shanafelt, MD
}

Mayo Clinic, 200 First Street SW, Rochester, MN 55905, USA

\begin{abstract}
The practice of surgical oncology provides opportunities for both personal distress as well as personal satisfaction. While many surgical oncologists experience career burnout, others derive great meaning and satisfaction from their work. In this article, we review the literature on surgeon burnout, discuss potential personal and professional consequences, and consider steps individual surgeons can take to promote personal and professional satisfaction.
\end{abstract}

Training for and practising the specialty of surgical oncology is stressful. During residency and fellowship many future surgeons cope with their stress by hoping things will get better when they enter practice. Taking such a "survival attitude" often weakens the relationships and personal activities that give life balance and meaning. Although they often intend to reclaim balance after the completion of training, many surgeons find they have simply exchanged one set of challenges (the demands of training) for another (the demands of starting a new practice). Many respond by maintaining a strategy of delayed gratification that assumes things will eventually spontaneously get better. Maintaining this strategy over a long period of time can lead to burnout, loss of enthusiasm for work, and atrophy of the personal activities and relationships that help provide purpose and meaning. Acknowledging the importance of personal well-being allows surgeons the opportunity to identify priorities, make decisions that balance personal and professional goals, and develop practice habits that can be sustainable through the course of their career.

Received November 2, 2007; accepted November 2, 2007; published online: December 12, 2007.

Address correspondence and reprint requests to: Tait Shanafelt, MD; E-mail: . Shanafelt.Tait@mayo.edu

Published by Springer Science+Business Media, LLC @ 2008 The Society of Surgical Oncology, Inc.
In this article, we review the literature on surgeon burnout, discuss potential personal and professional consequences, and consider steps individual surgeons can take to promote personal and professional satisfaction. Such strategies include identifying professional goals, optimizing career fit, identifying and managing stressors specific to practice type, determining and achieving the optimal personal work-life balance, and nurturing personal wellness strategies.

\section{A FAMILIAR STORY}

It is a story most surgeons know well, often from personal experience. A motivated colleague graduate enthusiastically embarks on their medical training with the hopes of making a difference. Out of a commitment to their studies and a desire to succeed, they willingly sacrifice some personal hobbies and interests in an effort to excel. After two years in the classroom, they are excited to finally begin clinical rotations and to focus on caring for patients.

During their surgical clerkship, they are awed by the knowledge, expertise, and judgment of the surgical residents. They are also inspired by the demonstrated commitment of these individuals to their profession. Everything is secondary to the needs of their patients and there are no excuses for factors that 
compromise quality of care. Although somewhat surprised by the occasional cynicism and irreverence of the residents, the student recognizes this as their way of coping with the intensity of their circumstances and he decides to pursue a career in surgery. He graduates from medical school near the top of his class with a great sense of accomplishment and matches into a respected surgical training program. He steels himself for the demands of postgraduate training. Although excited for the next phase of residency, he wonders when he will have time to start a family or pursue his personal interests.

The demands of residency are even greater than he expected. The days seem never-ending and overnight call is frequent and arduous. There is no life outside the hospital and his few hours away from work are spent sleeping, shopping for groceries, doing laundry, and reading the literature. There is no time for basketball and hiking - two of his favorite activities. Residency exacts a greater emotional toll than he had expected and sometimes he wonders how he survives. He forms strong bonds with his colleagues - the other surgical residents are the only individuals who understand what it is like. He sometimes finds himself having the same cynical thoughts he once found disturbing in other surgeons. At times he wonders if the training will demand more than he has to give and wonders if he chose the right specialty. He tries to ignore such thoughts, remembering all the good he has done, how much he has invested, and how much he respects his colleagues. He resolves to survive in the hope that life will get better after residency training.

Despite the challenges, he continues to excel professionally. He finds caring for patients with cancer particularly rewarding and decides to pursue a fellowship in surgical oncology. Toward the end of fellowship he begins a new relationship and gets married. He and his wife recognize they are not that young anymore and decide to start a family soon after they get married.

At the completion of fellowship he is overjoyed to finally be done with training and optimistic he will soon have more time to spend with his wife and children. He joins a prestigious practice and is eager to impress his new colleagues. As the junior member of the practice, he is assigned extra weekend and call responsibilities. The volume of clinical responsibilities is higher than he anticipated. Things do not feel that much different than training. He knows he is a good surgeon but starts to wonder if he is a good husband and father. Perhaps he should have pursued a different career...

\section{DELAYED GRATIFICATION (THINGS WILL GET BETTER WHEN...)}

The practice of surgery can be both challenging and rewarding. The discipline requires the surgeon to master a complex array of medical knowledge and develop an array of technical skills, judgment, leadership qualities, and the ability to make high stakes decisions under pressure. Surgical oncologists face the added challenges of working with cancer patients and are frequently (1) the supervisors of aggressive interventions that carry significant risk, (2) the bearers of bad news to patients, and (3) heavily exposed to patient suffering and death. Surgical oncologists willingly choose this discipline despite these challenges with the desire to help cure patients facing a life threatening condition.

The importance and altruism of this work have great appeal to committed physicians in training and surgical specialties have historically attracted the best and brightest medical school graduates. Surgery offers these physicians the opportunity to derive tremendous meaning from their work in addition to membership in a fraternity of dedicated and accomplished colleagues. Young surgeons typically embark upon their training in the surgical disciplines with the expectation that it will provide a fulfilling career that leads to both personal and professional satisfaction.

While these qualities of a career in surgical oncology provide the opportunity for tremendous career satisfaction, they can also be a source of great stress to the individual surgeon. Residency and fellowship training are a particularly arduous period when time for personal pursuits is incredibly limited. ${ }^{1,2}$ Many surgeons cope with this fact by assuming a survival mentality that anticipates that things will get better after the completion of training. As the story above illustrates, this is not necessarily true, as the first several years in practice are often demanding and consuming. This situation often leads to a sense of disillusionment and disappointment. Many surgeons respond by falling back on the familiar survival strategy of residency and hope that things will eventually get better. Unfortunately, this approach often perpetuates the problem and ultimately leads to career burnout.

\section{BURNOUT AMONG AMERICAN SURGEONS}

Physician distress wears many faces including anxiety, stress, broken relationships, depression, and burnout. ${ }^{3}$ Studies suggest that at the time of medical 
school matriculation, the mental health of medical students is similar to that of their nonmedical peers but that they experience an incremental increase in burnout with each year during medical school training which then crescendos during residency. ${ }^{4-6}$

Burnout is a syndrome of lack of interest/enthusiasm for work (emotional exhaustion), a tendency to treat people as if they were impersonal objects (depersonalization), and a sense that an individual's work is not meaningful or important (low sense of personal accomplishment). ${ }^{7}$ While the burnout syndrome can affect individuals in a variety of professions which require intense interaction with other people (police officers, social workers, teachers, nurses), its consequences may be particularly important in physicians. Studies suggest that burnout is associated with an increased risk of medical errors, ${ }^{8}$ suboptimal patient care, ${ }^{9,10}$ and reduced patient satisfaction. ${ }^{11-13}$ Burnout can also spill over into personal life and impact physician relationships and activities outside the professional domain, ${ }^{3}$ often leading surgeons to consider early retirement. ${ }^{14,15}$

While an increasing body of literature has chronicled the problem of burnout among physicians in general, less is known about the experience of burnout in American surgeons. In 2001 Campbell and colleagues surveyed the graduates of surgical residencies at the University of Michigan as well as members of a Midwest surgical association. ${ }^{14}$ Among respondents, $32 \%$ of practising surgeons met criteria for burnout. Contrary to the dogma that burnout was a late career phenomenon due to the accumulated experience of distress through the course of a career, younger surgeons were more susceptible to burnout than their older colleagues. ${ }^{14}$ This finding was consistent with similar results demonstrating a higher risk of burnout among younger physicians in other specialties. ${ }^{16}$ Although no relationship between burnout and case load or practice setting was present in the cross-sectional study, physicians who perceived an imbalance between their career and family/personal life and those who perceived a lack of autonomy at work had higher degrees of burnout. ${ }^{14}$

A more recent study of burnout among American transplant surgeons found a burnout rate of $38 \%$ when assessed using standardized instruments. ${ }^{17}$ The importance of autonomy was again underscored where the perception of having limited control over delivery of medical care was associated with higher degrees of burnout. ${ }^{17}$ Tension between personal and professional responsibilities was once again a critical contributor to burnout with those reporting higher sacrifice of personal time for work responsibilities experiencing higher burnout. ${ }^{17}$

The difficulty balancing personal and professional life is a common challenge for surgeons. In a study 1000 surgeons in Great Britain and Ireland published in 1990, having work interfere with personal life was rated the single greatest source of stress by surgeons followed by patient volume and responsibility for administrative tasks. ${ }^{18}$ Stress is often derived from conflict between two responsibilities (i.e., an emergency surgery occurring at the same time as an important family event) rather than the tasks themselves. Follow-up studies of surgeons in Great Britain and Ireland found that $71 \%$ had experienced a conflict between personal, clinical, and administrative responsibilities in the 3 weeks prior to the survey. ${ }^{15}$ Notably, when conflict arose between professional demands and their personal life, surgeons almost always gave a lower priority to their personal needs. ${ }^{15}$ Despite this self-sacrifice, $68 \%$ of surgeons reported the quality of care they provided patients suffered at least once per month because of their stress. ${ }^{15}$

How do these findings among general surgeons translate to surgical oncologists? Caring for patients with cancer involves unique challenges in addition to frequent exposure to patient death and suffering. Studies of practising medical oncologists suggest that 30-50\% experience burnout. ${ }^{16,19,20}$ To explore the burnout phenomenon among surgical oncologists in detail, we recently performed a survey of 1519 surgical oncologists who were members of the American Society of Surgical Oncology (SSO). ${ }^{21}$ Overall, 28\% of respondents met criteria for burnout, with younger surgeons once again at greater risk than their older colleagues. ${ }^{21}$ Greater exposure to clinical care (less than $25 \%$ devoted to research) and factors related to work load (number of cases per week) were associated with various domains of burnout on a comprehensive multivariate analysis. ${ }^{21}$ Strikingly, surgeon burnout was the single greatest predictor of dis-satisfaction with both career choice (being a physician) and specialty choice (surgical oncology) on multivariate analysis. $^{21}$

\section{RECOMMENDATIONS}

How should surgical oncologists respond to these findings? The first step to promoting personal satisfaction is honest self-appraisal to determine whether you have adopted a mentality of perpetual delayed gratification in your personal and professional life. Individuals should then identify personal and pro- 
TABLE 1. Questions to identify professional goals*
Why did I choose to become a physician?
Why did I choose to become a surgical oncologist?
What do I like most about my job?
What motivates me professionally?
By the end of my career, what three things do I hope to have accomplished?

* From Shanafelt et al. Shaping your career to maximize personal satisfaction in the practice of oncology. JCO 24(24):4020-6. Reprinted with permission of American Society for Clinical Oncology.

fessional goals so they can begin to make choices that help them achieve these objectives. To translate these concepts into an actionable plan, we propose a fivestep process of (1) identifying values, (2) career shaping/optimization, (3) identification and management of practice-specific stressors, (4) achieving balance between personal and professional goals, and (5) nurturing personal wellness strategies. ${ }^{22,31}$

\section{Identifying Values}

Individuals who have completed the training necessary to be a surgical oncologist have pursued a highly specialized career choice. Nonetheless, an array of different career and practice opportunities are available to these individuals including private practice, academic education, and translational or basic science (in academia or industry). The work content, day-today tasks, rewards, and demands on personal time of each of these career options are somewhat distinct. These differences may be viewed negatively or positively based on the preferences of the individual surgeon. Professional goals for many surgeons center on being a skilled healer, a medical educator, or advancing the care of patients through scientific discovery. We have proposed a series of questions that individual surgeons can consider to identify their greatest sources of professional motivation (Table 1). ${ }^{22}$

\section{Career Shaping/Optimization}

After identifying professional goals, it is essential for surgeons to make a critical appraisal of which practice type and setting provides them the greatest opportunity to achieve these goals. Rarely can an individual have it all. ${ }^{22}$ Individuals whose primary motivator is caring for patients are often most satisfied in private practice. If, however, individuals derive great satisfaction from being involved in resident and fellow education or clinical research, private practice positions are unlikely to allow adequate exposure to these areas for peak satisfaction. Once surgical on- cologists identify the optimal job type for their own preferences, they can evaluate various practice opportunities to see which opportunities within a given career category are most appealing.

Unfortunately, the training experience does not necessarily prepare surgical oncologists to make good career decisions. Residency and fellowship occur almost exclusively in academic medical centers where supervising physicians are typically clinician educators and/or academic researchers. These individuals are often the only role models with which residents and fellows have intimate contact, providing little insight into the rewards and challenges of private practice. $^{23}$ Despite their extensive clinical contact with academic surgeons, trainees are often unaware of the competitive nature of applying for and maintaining grant support and the challenges related to the process of academic promotion. Residents/fellows are also often exposed to a covert message that an academic career is "the best use of your talent" - an attitude that fails to recognize the optimal career path differs for each individual based on their talents, goals, and what activities they find most personally meaningful. Program directors or mentors who provide such a "be like me" approach to career counseling miss the opportunity to help future surgeons identify which career path would be most personally rewarding.

Once an individual determines the optimal practice type, it is important they remain mindful of why they chose this career path and avoid career drift. For example, a surgeon who chooses a career as a clinician educator because they derive great meaning from being involved in resident education must avoid becoming excessively involved in committee and administrative tasks that divert time away from those activities. Similarly, individuals in private practice who primarily desire to care for patients should avoid devoting too much time to practice management and administrative tasks.

Despite a vigilant effort to maintain focus on what is most personally meaningful, surgical oncologists should also recognize that interests may change during the course of their career. Individuals who once derived great pleasure from spending the majority of their time in the operating room may later find they enjoy the challenge of practice management or hospital administration. Similarly, academic surgeons may choose to place greater emphasis on education, research, or administration at different points during their career. Periodic assessment of which activities provide the greatest source of satisfaction and deliberate choices to emphasize these aspects of work provide the opportu- 
nity to refocus and maintain peak satisfaction through the course of a career.

\section{Awareness and Management of Practice-Specific Stressors}

After identifying values and selecting the optimal career type, it is important to recognize the challenges associated with this career path. Although productivity expectations, personnel issues, and keeping abreast of an expanding medical knowledge base are stresses for all career types, other challenges may vary by career category. Recognizing the challenges specific to each category allows surgeons the opportunity to manage them proactively.

Individuals in private practice often have a greater case volume, more frequent night and weekend call responsibilities, greater exposure to patient death/ suffering, and greater exposure to administrative and reimbursement issues. Such responsibilities can vary based on the size of the community in which they practice and whether individuals are in solo practice, part of a multispecialty group, or a member of an HMO. The method by which compensation is determined (salaried, performance based, mixture) can also greatly influence the pressure and workload of the individual surgeon.

Clinical educators often have a heavy case load, report feeling less valued by their institutional than translational or basic science researchers, and often deal with a somewhat nebulous path of promotion. ${ }^{24,25,26}$ The financial compensation of this career category is typically substantially less than private practice, an issue that is magnified by the fact many academic centers are in metropolitan areas with high a cost of living. Individuals who spend a significant amount of their time in scientific investigation are faced with maintaining grant support, a constant pressure to publish, and stress related to laboratory management (hiring/firing of personnel, managing interpersonal conflicts among subordinates, etc.). ${ }^{23,27-29}$

Surgical oncologists typically receive little training in how to manage these challenges. By recognizing the stressors specific to their career type, surgeons can manage these stressors through partnering, delegating, or pursuing additional training. Sharing clinical responsibilities with colleagues can help alleviate excessive night and weekend call. Delegating office management tasks and the business aspects of practice to administrators can free surgeons to focus on aspects of the work they find more meaningful. For academic researchers, pursing training in laboratory management or delegating some tasks to adminis- trators and accountants can be useful. ${ }^{27}$ Corroboration/partnership with scientists in other disciplines (epidemiology, statistics, molecular biology) can also help translational researchers enhance productivity. ${ }^{25,30}$ Academic researchers should clearly delineate their path for promotion with their department chair and define how the department will help them maintain adequate protected time for their research. $^{23,26}$ These suggestions represent a limited example of the types of strategies that can be used once an individual identifies the tasks they find least rewarding. Discussions with mentors and colleagues about how they have navigated similar challenges can also provide useful ideas.

\section{Achieving Balance between Personal and Professional Life}

Identifying professional values, choosing the right practice/career type, focusing on aspects of work that are most personally meaningful, and proactively managing the stressors of their career type can help individual surgeons optimize satisfaction in the professional sphere of their life. To achieve peak life satisfaction, however, each surgeon must also define the right personal work-life balance and nurture personal wellness strategies. Financial success, international fame and recognition, and personal interests/family are competing interests. It is tempting for individuals to believe they can "have it all" and pursue all activities with equal passion. This is typically a recipe for dissatisfaction. Achieving peak financial remuneration requires individuals perform more cases and build a larger clinical practice, which typically takes time away from family and personal pursuits. Similarly, achieving international acclaim as an expert involves sacrificing some personal activities to write grants, give talks, and write manuscripts.

It is important for individuals to acknowledge how a choice to pursue one aim may affect their ability to achieve others. Recognizing the competing nature of their ambitions provides surgeons the opportunity to determine which personal and professional goals are most important to them and allow them to prioritize their decisions. The right formula is unique for each individual and there is no single recipe for happiness. For example, two academic surgeons of equal ability who place different degrees of importance on their personal life may have widely different career/life paths. ${ }^{22}$ The surgeon who places greater emphasis on their career may spend more time traveling to give talks or serve on committees and will likely spend some personal time writing grants and manuscripts. A sec- 
TABLE 2. Questions to identify and integrate personal and professional values (adapted rrom $^{34-36}$ )

1 What is my greatest priority in life? Have I been living my life in a way that demonstrates this? $\diamond$

2 Where am I most irreplaceable? At home? At the hospital? Elsewhere?*

3 Do I have adequate balance between my personal and professional lives? ${ }^{\diamond}$

4 How much professional achievement (i.e., publications, prestige, financial compensation) am I willing to sacrifice to have more personal time or a better relationship with my family/children (be specific)?

5 Am I asking more of my spouse and children than I should?*

6 What kind of a legacy do I want to leave my children? ${ }^{\diamond}$

7 What person or activity have I been neglecting? $\diamond$

8 If I could relive the past year, what would I spend more time doing? What would I spend less time doing? What changes do I need to make to help this happen this year? ${ }^{\diamond}$

9 What would I like my life to be like in 10 years? $^{\mathrm{t}}$

10 What do I fear? ${ }^{\mathrm{t}}$

$\diamond$ From Shanafelt. $^{34}$

* From Myers. ${ }^{35,36}$

t From Clever. ${ }^{36}$

- From Shanafelt et al. Shaping your career to maximize personal satisfaction in the practice of oncology. JCO 24(24):4020-6. Reprinted with permission of American Society for Clinical Oncology.

ond surgeon who places greater priority on their relationship with family and personal hobbies may devote less personal time to such professional activities. It should not be surprising that the career trajectory and professional achievements of these individuals differ. The surgeon who chose to prioritize personal activities likely will have closer relationships with family and friends to compensate for their reduction in professional achievement relative to that of their colleague. Both of these paths may have equal potential for overall satisfaction depending on individual preferences and priorities. The principle is that individuals recognize the inherent tradeoffs of their decisions and consider both personal and professional accomplishments when they evaluate their overall success.

Similar to identifying professional goals, reflecting on a series of questions can help individuals identify personal goals and develop an integrated list of personal and professional values/priorities (Table 2). We have published a process through which individual physicians can translate their values/priorities into a specific action plan. ${ }^{22}$

\section{Nurturing Personal Wellness Strategies}

While identifying personal values and protecting personal time is necessary to achieve work-life balance, time away from work should be more than simply a chance to rest for another work day. Caring for self, cultivating relationships, and nurturing

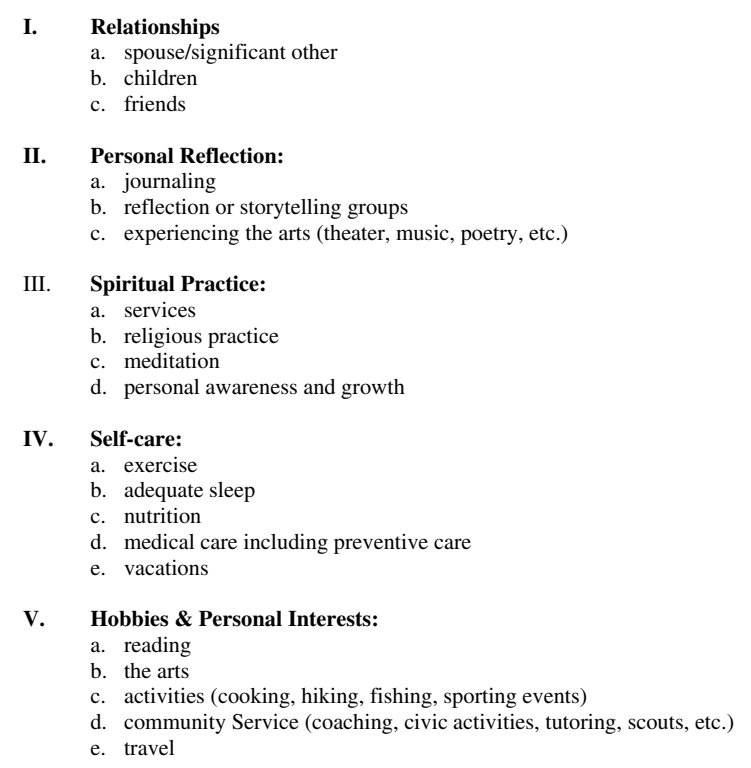

FIG. 1. Personal wellness strategies. Categories of personal wellness strategies reported to be useful in prior studies of physicians 313233 . Items listed under each category are intended to provide examples rather than be an inclusive list

personal interests is what makes time away from work meaningful and provides individuals the opportunity for achievement and personal growth outside of work. While innumerable activities can be valuable in this regard, prior studies suggest that the strategies used by individual physicians often share common themes (Fig. 1). ${ }^{31-33}$

\section{CONCLUSION}

The practice of surgical oncology offers the potential for tremendous personal and professional satisfaction. Few careers provide the opportunity to have such a profound impact on the lives of others and derive meaning from work. By identifying the priorities of both their personal and professional life, surgical oncologists can identify values, choose the optimal practice type, manage the stressors unique to that career path, determine the optimal personal work-life balance, and nurture their personal wellness. Such strategies can decrease the likelihood of burnout and help surgical oncologists achieve personal and professional satisfaction.

\section{REFERENCES}

1. Bunch WH, Dvonch VM, Storr CL, Baldwin DC Jr., Hughes $\mathrm{PH}$. The stresses of the surgical residency. J Surg Res 1992; $53: 268-71$. 
2. Zare S, Galanko J, Behrns K, et al. Psychological well-being of surgery resients before the 80-hour work week: a multiinstitutional study. J Am Coll Surg 2004; 198:633-40.

3. Shanafelt T, Sloan J, Habermann T. The Well-Being of Physicians. Am J Med 2003; I114:513-7.

4. Dyrbye LN, Thomas MR, Shanafelt TD. Medical student distress: causes, consequences, and proposed solutions. Mayo Clin Proc 2005; 80:1613-22.

5. Dyrbye LN, Thomas MR, Shanafelt TD. Systematic review of depression, anxiety, and other indicators of psychological distress among U.S. and Canadian medical students. Acad Med 2006; 81:354-73.

6. Dyrbye LN, Thomas MR, Huntington JL, et al. Personal life events and medical student burnout: a multicenter study. Acad Med 2006; 81:374-84.

7. Maslach C, Jackson S, Leiter M. Maslach Burnout Inventory Manual 3rd ed. Palo Alto CA: Consulting Psychologists; 1996.

8. West CP, Huschka MM, Novotny PJ, et al. Association of perceived medical errors with resident distress and empathy: a prospective longitudinal study. JAMA 2006; 296:1071-8.

9. Shanafelt TD, Bradley KA, Wipf JE, Back AL. Burnout and self-reported patient care in an internal medicine residency program. Ann Intern Med 2002; 136:358-67.

10. Firth-Cozens J, Greenhalgh J. Doctors' perceptions of the links between stress and lowered clinical care. Soc Sci Med 1997; $44: 1017-22$

11. Haas JS, Cook EF, Puopolo AL, Burstin HR, Cleary PD, Brennan TA. Is the professional satisfaction of general internists associated with patient satisfaction?. J Gen Intern Med 2000; 15:122-8.

12. Linn LS, Brook RH, Clark VA, Davies AR, Fink A, Kosecoff J. Physician and patient satisfaction as factors related to the organization of internal medicine group practices. Med Care $1985 ; 23: 1171-8$.

13. Lichtenstein RL. The job satisfaction and retention of physicians in organized settings: a literature review. Med Care Rev 1984; 41:139-79.

14. Campbell DA Jr., Sonnad SS, Eckhauser FE, Campbell KK, Greenfield LJ. Burnout among American surgeons. Surgery 2001; 130:696-702; discussion 702-695.

15. Kent GG, Johnson AG. Conflicting demands in surgical practice. Ann R Coll Surg Engl 1995; 77:235-8.

16. Ramirez AJ, Graham J, Richards MA, et al. Burnout and psychiatric disorder among cancer clinicians. Br J Cancer 1995; 71:1263-9.

17. Yost W, Eshelman A, Raoufi M, Aboulijoud M. A national study of burnout among American transplant surgeons. Transplant Proc 1995; 37:1399-401.

18. Green A, Duthie HL, Young HL, Peters TJ. Stress in surgeons. Br J Surg 1990; 77:1154-8.
19. Whippen DA, Canellos GP. Burnout syndrome in the practice of oncology: results of a random survey of 1,000 oncologists. $J$ Clin Oncol 1991; 9:1916-20.

20. Allegra C, Hall R, Yothers G. Prevalence of burnout in the U.S. oncology community: Results of a 2003 survey. J Oncol Pract 2005; 1:140-7.

21. Kuerer HM, Eberlein T, .J, Pollock RE, et al. Career satisfaction, practice patterns, and burnout among surgical oncologists: report on the quality of life of members of the Society of Surgical Oncology. Ann Surg Oncol 2007; 14:3043-53.

22. Shanafelt T, Chung H, White H, Lyckholm LJ. Shaping your career to maximize personal satisfaction in the practice of oncology. J Clin Oncol 2006; 24:4020-6.

23. Hoover EL. Mentoring surgeons in private and academic practice. Arch Surg 2005; 140:598-608.

24. Wright SM, Beasley BW. Motivating factors for academic physicians within departments of medicine. Mayo Clin Proc 2004; 79:1145-50.

25. Beasley B, Simon S, Wright S. A time to be promoted. J Gen Intern Med 2005; 21:123-9.

26. Beasley BW, Wright SM, Cofrancesco J Jr., Babbott SF, Thomas PA, Bass EB. Promotion criteria for clinician-educators in the United States and Canada. A survey of promotion committee chairpersons. JAMA 1997; 278:723-8.

27. Nathan DG. The several Cs of translational clinical research. $J$ Clin Invest 2005; 115:795-7.

28. Cech TR, Bond E. Managing your own lab. Science 2004; 304:1717.

29. Making the Right Moves: A Practical Guide to Scientific Managment for Postdocs and New Faculty. In: Institute HHM ed. wwwhhmiorg/labmanagment. Vol. 2005.

30. Goldstein JL, Brown MS. The clinical investigator: bewitched, bothered, and bewildered-but still beloved. J Clin Invest 1997; 99:2803-12.

31. Weiner EL, Swain GR, Wolf B, Gottlieb M. A qualitative study of physicians' own wellness-promotion practices. West $J$ Med 2001; 174:19-23.

32. Quill TE, Williamson PR. Healthy approaches to physician stress. Arch Intern Med 1990; 150:1857-61.

33. Shanafelt T, Novonty $\mathrm{P}$, Johnson ME, et al. The well-being and personal wellness promotion strategies of medical oncologists in the north central cancer treatment group (NCCTG). Oncology (Karger) 2005; 68:23-32.

34. NCCTG Shanafelt TD. Finding meaning, balance, and personal satisfaction in the practice of oncology. J Support Oncol 2005;3:157-62, 164.

35. NCCTG Myers MF. The well-being of physician relationships. West J Med 2001;174:30-3.

36. NCCTG Clever LH. A checklist for making good choices in trying - or tranquil - times. West J Med 2001;174:41-3. 